\title{
Postnatal Histogenesis of the Adrenal Medulla of the Hamster with Special Reference to the Functional Structure
}

\author{
By \\ Takashi Ito \\ Department of Anatomy, Nagoya University School of Medicine, \\ Nagoya, Japan \\ (Director: Prof. Dr. Ch. Togari)
}

In a previous paper (I to, '53), the adrenal medulla was studied mainly from the histogenetic point of view for the guinea pig. The reason why a similar study was again undertaken for the hamster is that the organ of this animal was expected to be different in many respects from that of other laboratory rodents. Recently G r a u m a n n ('56), working on the hamster, showed that the medulla of this animal has characteristic structures of special interest. It is hoped that the present work may provide some further information concerning the medulla of the hamster which is being used widely as a laboratory animal, and may contribute to a fuller understanding of this organ.

\section{Material and Methods}

The material employed was for the most part the same as used in the previous work dealing with postnatal histogenesis of the adrenal cortex (I t o, '56), but a part of it was newly prepared for this study. In total, the adrenal medullae of 145 hamsters of both sexes were studied. Hamsters were sacrificed at various ages ranging from birth to 200 days. The fixatives used were Bou in's, Cia c ci o's, Z e n$\mathrm{k}$ e r's fluids, $Z$ e $\mathrm{n}$ k e r-formol and $Z$ e $\mathrm{n}$ k e r-formol-acetic acid mixture. The fixation in Ciaccio's fluid or $\mathrm{Zenker-formol} \mathrm{was} \mathrm{mostly}$ followed by post-chromation in $3 \%$ potassium bichromate for four to seven days or equal parts of $5 \%$ potassium bichromate and $2 \%$ chrome alum for two days, respectively. 
The adrenals were imbedded in paraffin, cut at $5 \mu$ and mounted serially. The stains commonly employed were $\mathrm{M}$ a y e $r$ 's hematoxylin and eosin and $\mathrm{Heide} \mathrm{nh}$ i n's iron hematoxylin. In addition, some of the sections were stained with PAS (periodic acid-Schiff) technique,

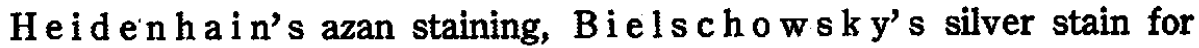
argyrophile fibers and Unna-Pappenheim's procedure.

\section{Observations}

\section{Postnatal histogenesis}

At birth, the adrenal medulla occupies an almost central portion of the gland, being intermingled with large amounts of cortical tissues. The cells constituting the medulla are arranged in irregularly shaped masses or cords. They are composed of two types; sympathogonia, undifferentiated sympathetic cells and pheochromoblasts, undifferentiated medullary cells. The sympathogonia are few in number. They are aggregated in small cell clusters in the periphery of the medulla. Their cytoplasm is scarce and slightly basophilic, forming a thin rim around the nucleus. The nuclei are small, oval and rich in chromatin. Their nucleoli are very characteristic in appearance; they appear as four to six prominent basophilic spheres of relatively large size (fig. 1). The sympathogonia present occasional degenerative figures which appear as fragmented masses with deeply staining nuclear debris. The pheochromoblasts constitute the majority of the medullary elements. They are larger in cell and nuclear size than the sympathogonia. Their nuclei are lighter, and contain several nucleoli or chromatin particles. The nucleoli are not so prominent as those of the sympathogonia. Mitotic division is often seen in the pheochromoblasts. After application of PAS reagent, the cytoplasm of these cells generally stains purple red, although varying in tinctorial degree in different cells.

At one to three days, the medullary tissues are swarmed more centrally than in the preceeding stage. The intermingling cortical tissues are reduced in amount. Blood vessels running between the medullary tissues appear sinusoidal with a thin wall and a relatively wide lumen. The medulla is composed of pheochromoblasts. The sympathogonia have already disappeared at this age. The majority of them have been transformed into pheochromoblasts, and some few differentiated in the direction of the ganglion cells. The latter forms are sympathoplasts, the development of which was described in a previous paper (I to, '54). The pheochromoblasts vary in degree of different- 
iation. The relatively immature forms arranged in small groups exist in the periphery of the medulla. More centrally in the medulla the cells show more advanced differentiation. The relatively differentiated cells are polygonal or columnar with considerably distinct cell boundaries. Their coarsely granular cytoplasm is increased in amount with advancing differentiation. When stained with PAS, these cells give stronger reactions than do the relatively undifferentiated ones. In three-day-old animals, some few masses of the medullary cells contain irregularly shaped spaces of very small size.

At 4-5 days, the medulla is separated from the cortex, although small numbers of cortical cells are scattered singly or in small groups among the medullary tissues. The medullary cells at a similar degree of differentiation tend to be in groups. The relatively immature cells near the cortico-medullary boundary are small in size and, consequently, their nuclei are closely packed. In the masses of the medullary cells there occur occasional intercellular spaces of small size.

At 6-7 days, the cells of the medulla generally show further differentiation when compared with those in the previous stage. Particularly, toward the central area of the medulla the cells become developed with increased cell size. Their general shape is polygonal or polyhedral with a slightly eccentric nucleus. When abutting the blood vessels, the cells are sometimes columnar-shaped with a tendency for the nucleus to be placed eccentrically at the distal pole opposite the vessel wall. The cytoplasm of the medullary cells is finely granular and moderately basophilic. It shows varying degrees of pink purple staining with PAS. The nucleus is large, round or oval and chromatinpoor. It contains, as a rule, several small basophilic nucleoli. The masses of the medullary cells show occasional spaces of varying size and shape. Some spaces are considerably enlarged, and their wall is composed of a layer of cuboidal or columnar cells (fig. 2). The masses with such enlarged spaces appear like follicles. Their lumen commonly contains no staining material, but sometimes possesses eosinophilic materials or erythrocytes. Among the medullary cells there are rarely found cells with very large nucleus measuring more than $10 \mu$ in diameter. The nuclear membrane of such nuclei sometimes exhibits a deep indentation.

At 8-10 days, the medullary cells, particularly those of angular shape, give stronger reactions with PAS than in the former stage. The immature cells of relatively small size generally appear in groups in the medulla, although varying in amount in different individuals. 
At 12-13 days, the cortico-medullary boundary is almost even and distinct. The cortical cells intermingling between the medullary cells are very few in number. The medullary cells have a moderately abundant cytoplasm, which stains with PAS more conspicuously than before. Their nuclei are large, round or oval, and possess delicate network of chromatin and two to four nucleoli. In many nuclei, one of the nucleoli appears as an eosinophilic sphere which is free within the nucleus, and the remainder as somewhat smaller basophilic spheres often adherent to the nuclear membrane. The medullary cells often exhibit a follicular arrangement with a wide lumen. The lumen frequently contains erythrocytes. Especially in the periphery of the medulla the lumen is sometimes extremely large and is lined with somewhat flattened cells." Such lumen usually contains acidophilic material often intermingled with vacuoles especially at the periphery. In addition, spaces of small though varying sizes are seen in some masses of the medullary cells. Such intercellular spaces appear to develop from dissociation of the cells.

At 15 days, the follicle formation is frequent rather in the central region of the medulla; but a few cavities of extremely large size measuring $40-70 \mu$, sometimes over $90 \mu$, in diameter occur in the periphery:

At 18-20 days, the medullary cells generally continue to undergo enlargement. The cells in the periphery sometimes show a tendency to be arranged in compact masses. These cells have a slightly clearer cytoplasm than do those in the central region. Large cavities such as those seen in the former stages are no longer present. The cells in the central region of the medulla are often arranged in a follicular pattern. Their general shape is columnar. The PAS reaction of the medullary cells are generally less conspicuous than in the former stage. Especially the peripheral clear cells are scarcely stained with this staining except in their juxtanuclear area which shows a faint reaction.

At 25-30 days, the medullary cells are composed of two types as seen in the adult; polygonal clear cells arranged in compact masses and columnar cells commonly arranged as follicles or in cords. The former are present mainly in the periphery of the medulla, whereas the latter, exceeding the former in amount, are found throughout the medulla. Both types, however, are continuous with one another in appearance.

At 35 days, the medulla practically presents features typical of the mature form below described. However, immature cells of smaller 
size, though usually few in number, remain in small groups even at this stage. These cells have a relatively basophilic cytoplasm and somewhat closely packed nucleus. The nucleus contains three to six basophilic nucleoli attached to the nuclear wall. Such cells become reduced in number until they finally disappear at 40 to 50 days of age.

\section{Fine structure}

As above described, the medulla developmentally attains an essentially mature state at about 35 days of age. Thereafter, there are little further changes in the finer structures of this organ in advancing age until 200 days, so far dealt in the present study. In the following, the fine structures of the mature medulla will be described in some detail.

The parenchyma of the medulla is arranged in masses, cords of cells and as follicles (figs. 3-4). These cell groups and follicles, enclosed by a network of argyrophile fibrils, are surrounded by anastomosing blood vessels which appear sinusoidal with a relatively wide lumen. Owing to differences in the arrangement and cytological features of the medullary cells, two types can be defined in practice, although transitional with each other. In regard to relative amounts of the respective cell types, considerable variations exist in different individuals even at similar ages and in the same sex. It is probable that these individual differences depend on the functional state of the medulla.

The cells of one type are arranged usually in compact masses and are present in the periphery of the medulla rather than in the center (fig. 3). They are generally large and polygonal-shaped, although frequently varying in size and shape. Their cytoplasm is very lightly stained except for the cap-like area adjacent to the eccentrically located nucleus (figs. 5-6). The juxtanuclear area is eosinophilic and presents a faint PAS reaction. Such area often contains basophilic granular materials around the periphery, which coincide with "Randkörper" described by Bargman ('53) in the medullary cells of the hedgehog, except for the side adjacent to the nucleus (fig. 6). With Un n aPappenheim's stain these materials are stained intensely with pyronin. When stained with iron-hematoxylin after $\mathrm{Z}$ e n $\mathrm{k}$ e r-formol or $\mathrm{Ci}$ a c c i o fixation, the cytoplasm of these peripheral cells is seen to contain fine vacuoles in large quantities except for the dense-staining juxtanuclear area (fig. 7). The cells appear expanded when filled with large amounts of vacuoles. Furthermore, in sections prepared by 
this procedure, minute spaces are sometimes demonstrated between the cells. Some spaces of extremely small size occur as short intercellular canalicules ending blindly between the sides of adjoining cells (fig. 7). In addition, intercellular spaces of larger sizes sometimes occur, too. When a relatively large space appears, the cells, like the cells of the other type to be described below, often show a follicularlike arrangement around it. The spaces are not always situated centrally in the cell masses, but are sometimes located eccentrically directly close to the enclosing layer of connective tissue.

The medullary cells of another type are arranged usually as follicles or in cords, but not infrequently as irregularly shaped masses. The follicles contain lumen of variable sizes and shapes, and are lined with one or occasionally two or three layers of cells (fig. 4). The cords or masses contain occasional narrow spaces in their axis or interior. When serially examined, the follicles and cords or masses are often continuous with one another, and the lumen of the follicles occasionally commnicates with the spaces of the cords or masses. In any case, the follicular arrangement may be regarded as representative of this type of cells. The medullary cells arranged in these patterns are generally high to low columnar in shape, although not infrequently more or less irregular-shaped. They show an interesting polarity. The nucleus is situated eccentrically at the apical pole of the cell directed toward the lumen of the follicles or the axis of the cell cords or masses, and the cytoplasm is extremely abundant at the opposite pole facing the blood vessel (figs. 8-10). The cytoplasm is generally basophile and granular except for the infranuclear area which stains more or less homogeneously with eosin. In usual sections, therefore, the cells appear rather dark in contrast to the light cells of the above-mentioned type. They generally present no or little reaction with PAS, although some are more or less PAS-positive. The apical area of the cytoplasm, particularly that of cells forming the follicles, is generally narrow, although varying to some extent in amount. It often appears foamy but very fragile. But by appropriate methods, particularly iron-hematoxylin after $\mathrm{Ci}$ a c ci o or $Z$ e $\mathrm{n} \mathrm{k} \mathrm{r-formol} \mathrm{fixation,} \mathrm{this} \mathrm{area} \mathrm{is} \mathrm{often} \mathrm{found} \mathrm{to} \mathrm{possess}$ varying degrees of accumulation of vacuoles (figs. 9-10). These vacuoles vary considerably in amount from cell to cell. When large numbers of vacuoles have accumulated, the free surface of the cell bulges and projects toward the lumen. Further, the vacuoles are seen extruded from the cell surface, or their content appears to be thrown out, owing to dissolution of the apex of the cell, into the lumen (fig. 10). On 
the other hand, when little vacuoles are contained, the apical area appears as a very thin cytoplasmic rim above the nucleus. Thus, the cells forming the follicles present visible indications of secretory activity at the apical part, the height of which appears to vary by the state of activity. Degenerating cells are occasionally found among the medullary cells lining the follicles. They are often desquamated from the wall of the follicles. Probably due to desquamation of the cells, the lumen of the follicles is sometimes close to the surrounding blood vessels only through a very delicate layer of connective tissue. The lumen of the follicles frequently contains no material stained with ordinary procedures. In some follicles, however, it is filled with homogeneous or granular materials which stain with eosin in hematoxylin and eosin sections. In such cases, vacuoles of relatively large size are often found in considerable though varying numbers within the lumen, particularly at the periphery. Furthermore, blood cells, especially erythrocytes, are often present in the lumen, and at times so abundantly as to fill the whole lumen (fig. 8). In addition, there are occasional degenerating or dead cells desquamated from the follicle wall or rare phagocytic cells laden with yellowish brown pigment granules.

The nuclei of the medullary cells are essentially similar in morphology in both types of cells above described. The nuclei exhibit an eccentric position in the cell (figs. 5-10). They are, as a rule, large, round or oval and vesicular. Their nucleoli are somewhat variable in number and appearance. For instance, some nuclei contain one to three nucleoli which occur usually as small eosinophilic spheres enveloped with a very delicate shell of chromatin, and others contain a vague or unrecognizable nucleolus. The nucleoli, if present, are dispersed within the nucleus and often attached to the nuclear membrane. An interesting feature characteristic of the nuclei of the well-developed medullary cells is the common occurrence of nuclear deformation. The nuclear deformation begins to appear at 45 to 50 days of age, although at first relatively slight in degree and few in number. With advancing age, nuclei with deformation become gradually increased in number and the degree of deformation becomes higher, until at 75-80 days nuclei showing various degrees of deformation are of common occurrence. Finally, in most hamsters older than 100 days, when examined under high magnification, the great majority of the nuclei are characteristically deformed. The nuclear deformation is extremely varied in appearance, ranging from simple to complex indentations. The indentations vary in depth. It is often so deep as to penetrate into the nu- 
cleus like a canalicule (fig. 11). Two or more indentations are not rarely present in a single nucleus. The deep indentation is sometimes split into two or more branches and bent in course. Some indentations are so deep that they extend through almost the entire diameter of the nucleus and rarely even penetrate it. The content of the indentations, deep or superificial, stains relatively intensely with eosin. There are various transitions between the indentations and nucleoli. The indentations seem to be derived at least in part from the nucleoli in the following manner. A nucleolus sends a very fine projection, which finally extends as far as the nuclear membrane. Meanwhile, the nucleolar substance gradually moves through the projection. The nuclear membrane attached by the projection becomes indistinct, finally to disappear. There are also superficial indentations that appear to develop directly from the nucleolus which is attached to the nuclear membrane. In every case of these indentations, the nucleolus comes to open into the cytoplasm after local disappearance of the nuclear membrane. Furtheremore, there is also direct extrusion of nucleoli from the nucleus into the cytoplasm. In such case, nucleoli become accumulated at one side of the nucleus, some of them being in contact with the nuclear membrane. Subsequently, they become gradually swollen, protruded outward from the nuclear surface, and finally extruded into the cytoplasm (fig. 12). The nuclear surface where the protrusion of nucleoli occurs is indentated with minute finger-like projections, and the nuclear membrane sometimes appears more delicate and less distinct here than in other parts. The fate of the nucleoli extruded directly into the cytoplasm cannot be pursued, although some of them rarely persist as small spheres in the cytoplasm. In general, they seem to disappear shortly after extrusion.

Most, but not all, of the indentations are located on the nuclear side which is directed toward the dense-staining juxtanuclear area in the peripheral light cells or basalward in the columnar cells arranged as follicles.

The medullary cells undergo mitosis even after the organ has attained histological maturity, although their mitotic figures, of course, become reduced in number with advancing age. In hamasters aged more than 100 days, mitotic figures are so rare that they might be overlooked without careful examination through serial sections. At any rate, however, they occur in nearly all stages until the age of 200 days.

The nuclei of the medullary cells rarely contain an inclusion which 
occurs as an eosinophilic sphere usually of large size (fig. 13). There are intermediate transitions between the intranuclear inclusions and nucleoli. There are rarely two or three nucleoli in addition to a large inclusion in a single nucleus. The intranuclear spheres of extremely large size, though being of uncommon occurrence, fill almost the whole nucleus.

The medullary cells rarely possess colloid materials in the cytoplasm (fig. 14). Such materials were described as colloid by B a r g$\mathrm{m}$ a $\mathrm{n}$ ('53) in the hedgehog and recently recognized by $\mathrm{Gra}$ u $\mathrm{m}$ a $\mathrm{n}$ ('56) in the hamster. The occurrence of these materials, however, seems to be exceptional rather than normal, because they were found only in a few of the cases examined.

\section{Discussion}

\section{Differentiation of the medullary cells}

It is common knowledge that the adrenal medulla arises from the sympathetic tissue. The cellular elements of the medulla undergo a gradual and continuous transformation during development. The cell series from the earliest to the fully developed elements are generally classified into three forms; namely, sympathogonia, pheochromoblasts and pheochromocytes (Dietrich and Sieg mund, '26). The cytogenesis of the medullary cells begins immediately after migration of the most primitive cells forming the primordium of the medulla into the developing cortex in early fetal life, and is achieved in postnatal life. In rodents, the age when the differentiation is completed is considerably varied in different species.

The sympathogonia are the most primitive sympathetic cells, which are the stem cells giving rise to both the medullary cells and ganglion cells of the medulla. As already described, these cells in the hamster are so characteritic in morphological features that they can readily be identified in sections stained with hematoxylin and eosin. They appear to be almost, the same in morphology as those in other rodents, such as mice (Bessho, '27a), rats (Bessho, '27b), and guinea pigs (I t o, '53). However, the period of their persistence is somewhat varied in each animal. In the mouse and rat, the sympathogonia persist until the age of 10 days, while in the guinea pig they disappear earlier toward the end of intra-uterine life. In postnatal hamsters, the sympathogonia are present only at birth, and then disappear mainly through transformation into more differentiated forms. 
The second stage in differentiation directed toward the medullary cells is known as pheochromoblasts. In the development of the medullary cell series, the pheochromoblasts are intermediate forms between the sympathogonia and the last developmental stage, the pheochromocytes. Therefore, they are somewhat varied in appearance according to the degree of maturation. The relatively immature forms appear as small cells closely packed like the sympathogonia. Morphologically, however, the pheochromoblasts can readily be distinguished from the sympathogonia, because the latter forms possess exceedingly characteritic features as repeatedly noted. With progress in maturation, the pheochromoblasts become gradually increased in size and differentiated in cytological features. Thus the relatively mature pheochromoblasts come to bear some resemblance in appearance to the last developmental stage or pheochromocytes. The common cytological evidence for transformation of pheochromoblasts into pheochromocytes is, of course, the appearance of chromaffin reaction. In the present study, however, the chromaffin reaction was not systematically tested for all the stages examined. The medulla of the hamster apparently reacts far less intensely to the test than does that of other rodents. In the present work, attention was directed to PAS-staining as an important method for studying the developing medullary cells. In a recent publication, $\mathrm{G} \mathrm{r}$ a u $\mathrm{m}$ a $\mathrm{n}$ n ('56), applying the PAS technique after Helly's fixation, reported, in the hamster, that the immature medulla at birth is stained positively with this staining, and that the PAS-positive materials become gradually increased in staining intensity toward the end of the second week but suddenly reduced after the animal has become independent at three weeks of age. According to this author, the PAS-positive material is regarded as being related with the hormone of the medulla or adrenalin boby, and its decline that occurs simultaneously with independence of the animal is due to turning of the material to a PAS-negative form. Further, he noted that since the decline of the PAS-reaction occurs in parallel with the appearance of chromaffin granules, the PAS-positive material is presumed to lose its staining ability for PAS by being combined with the chromaffin granules. The findings of $\mathrm{Gr}$ a u m a $\mathrm{n}$ are suggestive that the medullary cells do not become chromaffin until they become PAS-negative. In other words, the PAS-positive cells in development of the medullary cell series may well be regarded as representing the immature forms known as pheochromoblasts. For these reasons, from the standpoint of this study, it may be said that the PAS technique is effective in differentiating pheochromoblasts from 
pheochromocytes. According to the results obtained, the immature forms stain positively with PAS even in preparations fixed in Bou i n's fluid. These cells are small at first. As the maturation proceeds, they become progressively increased in volume and acquire a greater tendency to stain with PAS until they show strongest PAS reaction at 12-13 days. From 18-20 days, however, the reaction declines in degree. Then the cells gradually assume the features of mature forms until finally the appearance of the adult medulla is achieved at approximately 30-35 days, although the immature forms of smaller size still remain only in small numbers.

\section{Functional structure of the medulla \\ a) Follicles}

Follicles in endocrine organs are a peculiar structure owing to regular arrangement of the parenchymal cells. They are known to occur not only in the thyroid gland but also in certain other endocrine glands. For the adrenal medulla, B a r g m a n n ('53) recently described the occurrence of follicles in the hedgehog. Except for his study, there had been almost no report regarding the follicles in the medulla, until more recently $\mathrm{Gr}$ a u m a n $\mathrm{n}$ ('56) published a detailed description on the medullary follicles in the hamster. G r a u mann ('56) mentioned that the formation of follicles is due to degeneration, associated with secretion, of the medullary cells axially present in solid masses, and that the follicles first appear at $\mathbf{1 1}$ days of age. According to my observations, the follicles appear early in life. At three days, narrow spaces of irregular shape arise within some few masses of medullary cells. Such spaces become rapidly increased in number and size. As the space enlarges, the cells become arranged more or less radially around it. Thus the medulla comes first to contain follicles at 7 days. Then the follicles gradually increase in number, and the medullary cells lining the follicles become further differentiated until essentially mature follicles are formed at approximately 20 days of age. Thus the formation of follicles in early life seems to be primarily due to autonomous re-arrangement of the medullary cells following enlargement of the lumen. In the fully developed medulla, the follicles appear to undergo morphological changes probably according to the functional activity. There are many transitions between the follicles and solid cords or masses. The transformation between both appears to occur as the result of changes in the size of the axial lumen. The gradual enlargement of the axial lumen of the solid formations appears to 
follow the same pattern noted by G r a u man $\mathrm{n}$ ('56), presumably resulting from the secretory process in the axial portion of the cells.

Regarding the cytological features of the medullary cells lining the follicles, the present observations are essentially in accord with those of $\mathrm{G} \mathrm{r}$ a u m a $\mathrm{n} n$ ('56). The visible indication of secretory activity of the medullary cells in the follicles is a fine vacuole at the apical portion of the cell, because the vacuoles accumulate at the apical portion of the cell, and subsequently are released into the follicular lumen. Such process of secretion is somewhat peculiar in mode, although appearing like an apocrine. The vacuoles are discharged by extrusion from the free surface of the cell or through dissolution of the apical cytoplasm. In no case is the apical portion with the vacuoles pinched off as in the apocrine gland. The findings that the secretion elaborated by the medullary cells reaches the follicular lumen in the first place are of particular interest in connection with the mode of secretion of the medulla in the hamster, as pointed by $\mathrm{G} \mathrm{ra} \mathrm{u} \mathrm{m} \mathrm{a} \mathrm{n} \mathrm{n}$ ('56). In the follicles, the secretion of the medullary cells is not poured directly into the blood stream as is generally presumed in the common endocrine glands. The secretory materials poured into the lumen are probably passed secondly into the blood stream. The close relationship between the lumen and blood stream can be assumed from the fact that the lumen is often in contact with the blood vessel only through a declicate layer of connective tissue in parts where the cells of the follicle wall are desquamated and lacking. Moreover, the findings that the lumen often contains blood cells, especially erythrocytes, in varying numbers also offer support for the above assumption.

\section{b) Secretion of the medullary cells}

In many animals, the medullary cells are classified into two types which have been called respectively light and dark cells. Concerning these two cell types, B a ch ma n n ('54) gave a detailed review of the literature in his voluminous publication. At present it is still uncertain whether these two types of cells are different in cell function or they represent merely different stages of functional activity. In a previous study dealing with the guines pig's medulla, I observed the presence of dark cells which were regarded as being in a phase of functional activity (I to, '53). On the other hand, some recent investigators such Bänder ('50a, '50b) and E ränk ö ('52) considered the two cell types, demonstrated by a variety of staining methods, to be related to secretion of two different secretory products; adrenalin and 
noradrenalin. According to B ä n de r ('50a, '50b), however, the two types of cells do not exist in all species so far examined. If this is the case, the presence of two cell types would not be constant in all animals, and consequently, disagreement of earlier studies concerning this problem might be ascribable to difference of animal species employed. In any case, the study of each individual species in detail will be an essential contribution to this question. In the medulla of the hamster, there are two types of parenchymal cells, although transitions can be found between both. The cells of one type constitute the follicles as already described. They are generally columnar in shape, and their cytoplasm is basophilic and finely granular. The cells of the other type are arranged mostly in compact masses and are present predominantly in the periphery of the medulla. They are generally polygonal in shape, and usually have a light cytoplasm. The presence of these two types of medullary cells in the hamster was briefly referred to by $\mathrm{K} \mathrm{nigge} \mathrm{('54).} \mathrm{More} \mathrm{recently} \mathrm{G} \mathrm{r} \mathrm{a} \mathrm{u} \mathrm{ma} \mathrm{n} \mathrm{n} \mathrm{('56)} \mathrm{also}$ noted, in this animal, that in addition to the follicles, large cells with coarsely granular cytoplasm are found in the periphery of the medulla.

The secretory activity of the medullary cells has morphologically been judged mainly from two cytological features; chromaffin reaction and cytoplasmic vacuoles. Especially the cytoplasmic vacuoles are regarded secretory droplets or liquefying products which are to be discharged (S t a e m mler, '33; E n jo, '47a; I t o, '53). In the hamster, too, this is confirmed in the medullary cells lining the follicles. On the other hand, the lightly staining cells arranged in compact masses also appear to owe their pale appearance to abundant accumulation of cytoplasmic vacuoles. In view of the above concept and the findings obtained in the follicles, the vacuoles in the peripheral, lightly staning cells also may well be supposed to be secretory droplets. Furthermore, the solid masses often show narrow though variously sized spaces between the medullary cells. The most minute spaces frequently resemble in appearance the intercellular secretory capillaries known in some exocrine glands. This fact seems to suggest the possibility that the peripheral light cells secrete their secretory products into the intercellular spaces and not directly into the blood stream. In summary, the foregoing descriptions are highly suggestive that the process and mode of secretion are essentially similar in both types of medullary cells in the hamster. Firstly, the secretory materials appear to liquefy into vacuoles in the cytoplasm. Therefore, the vacuoles serve as cyto. logical criterion for functional activity of the medullary cells, Second- 
ly, the secretory products are poured first intercellularly rather than directly into the blood stream. In any type of medullary cells, the mode of secretion may well be termed indirect secretion as called by Gra u mann ('56).

In connection with the modus of secretion of the medullary cells, the intercellular spaces are of special interest. Formerly L y dia Félic in e ('02, '04) reported the existence of intercellular canalicules in the adrenal medulla of several animals. Little attention, however, has been paid to this work. The present findings indicate that at least in the hamster the intercellular spaces noted by F élicine ('02, '04) actually exist. In a relative sense, the follicular lumen also is interpreted as an exceedingly wide intercellular space. In'this connection, it is a question of compelling interest whether or not the intercellular spaces can actually be found also for other animals. In the adrenal medulla of the mouse, I could recognize minute intercellular spaces which appeared like secretory capillaries (I t o, unpublished). At present the study is being extended to other animals.

\section{c) Nuclei of the medullary cells}

The nuclei of the medullary cells of the hamster frequently present a very characteristic feature of special interest, that is, peculiar deformation. Such nuclear deformation occurs in the nuclei of the cells with highly developed activities. The possible significance of the nuclear deformation may be understood in the light of the modern concept that the nucleus, especially nucleolus, plays a direct role in cell function such as protein synthesis. Concerning the emergence of nucleolar substance into the cytoplasm, there have been several references in the literature for various organs (For extensive references and review see: A $1 \mathrm{tm}$ a $\mathrm{n} \mathrm{n}$, '52, '55; $\mathrm{H}$ a $\mathrm{m} \mathrm{a} \mathrm{z}$ a k i, '54). At present, particular interest attaches to such phenomenon in relation to the above-mentioned concept, because the phenomenon would be regarded as presenting morphological evidence for the concept. Recently A.1 t m a n n ('52) analysed in detail nuclear structural changes undergoing during a secretory cycle in the acinar cells of the pancreas, and morphologically elucidated that the nuclei discharge the nucleolar substance directly into the cytoplasm during cellular protein synthesis. Subsequently, in a comprehensive monograph on the nucleus, $\mathrm{H} \mathrm{a} \mathrm{ma-}$ $z$ a k i ('54) gave a detailed description, from the morphological stand. point, of the emission of nuclear substance into the cytoplasm. In the medullary cells of the human adrenal, $\mathrm{En} \mathrm{jo} \mathrm{('47b)} \mathrm{reported} \mathrm{that} \mathrm{the}$ 
nucleolar vesicles of varying sizes are often extruded from the nucleus into the cytoplasm. According to my observations, the nuclear deformation in the medullary cells of the hamster appears probably in parts due to the extrusion of the nucleolar substance into the cytoplasm. In some cases, nucleoli are found to be directly extruded from the nucleus into the cytoplasm. Furthermore, the location of the deformation in the nucleus is typical in most cases. In the lightly staining cells, the nuclear deformation such as indentation occurs predominantly on the nuclear surface directed toward the condensed cap-like area of the cytoplasm, and in the columnar cells of the follicles, it is generally found on the surface directed basalwards. The juxtanuclear area facing the nuclear deformation is peculiar in appearance, and, consequently, probably in function. Especially the area in the light cells appears to correspond to the "paranuclear complex" described by $\mathrm{Bargmann}$ ('53) in the medullary cells of the hedgehog. In the hamster, G r a u m a n n ('56) considered this area to be a Golgi-zone where the secretory products are formed. Thus the juxtanuclear area is morphologically distinguishable from the remainder of the cytoplasm and seems functionally to be related to cellular activities. In this connection, it is of particular interest to note that the nuclear deformation lies close to the juxtanuclear area, because these observations could be regarded as evidence that the nucleus likely plays a part in functional activity of the cell probably by discharging the nucleolar materials into such functionally significant area of the cytoplasm.

The nuclei of the medullary cells rarely contain an intranuclear inclusion that appears commonly as an eosinophilic sphere of considerably large size. The intranuclear inclusion is considered to be derived from the nucleolus, because transition forms from the nucleoli can be recognized. The formation of the inclusion seems to result from storage of the nucleolar materials, as presumed by A I t m a $\mathrm{n}$ ('52).

Regarding division of the medullary cells, amitosis is said to be the common form. Cla ra ('37); working on the medulla of man, stated that the replenishment of the degenerated cells takes place by amitosis. Subsequently, $\mathrm{E} n$ jo ('47b), in agreement with $\mathrm{Cl}$ a r a, noted in man that the differentiated medullary cells undergo amitosis and no mitosis. The pictures presented as amitotic figures in her paper are very similar to the nuclear deformation observed in the hamster. The nuclear deformation, however, cannot be regarded as representing an amitotic figure. In the adrenal medulla of the hamster, degenerating and dead cells are sometimes present. Their replenishment appears 
to be provided by mitotic activity of the medullary cells, because mitotic figures, though in very small numbers, persist even in adults.

\section{Summary}

The adrenal medullae of hamsters of both sexes progressing in ages from birth to 200 days were studied from the histogenetic point of view, and the functional structure was considered with special emphasis.

The medullary cells differentiate from sympathogonia after passing through the stage of pheochromoblasts. The sympathogonia are the most primitive forms with very characteristic features. In postnatal life they are present only in the newborn medulla. The pheochromoblasts are PAS-positive, undifferentiated medullary cells, and, consequently, the immature medulla composed mainly of these cells in early life is stained positively with the PAS method. The medulla becomes stronger in PAS-staining until the age of 12-13 days. With progress of the differentiation, the PAS-reaction of these cells rapidly declines in intensity, until finally the medullary cells show no or little staining ability for PAS when they have differentiated into the last developmental stage or pheochromocytes. Thus the medulla developmentally reaches an almost definitive state at approximately 30-50 days of age.

In the medulla of adult hamsters there are two types of parenchymal cells; namely, large polygonal lightly-staining cells arranged commonly in compact masses mainly in the periphery of the medulla and columnar finely granular cells arranged as follicles or in cords or masses. These two types of cells are transitional with one another, and considerable variation exists in regard to relative amounts of the respective cell types from gland to gland. Both types of medullary cells are essentially similar in process and mode of secretion. In any type the secretory materials appear to liquefy into vacuoles in the cytoplasm. The mode of secretion is regarded as an indirect one in both types; the medullary cells appear to pour their secretory products first intercellularly and not directly into the blood stream. In this connection, the follicles, characteristic of the medulla of this animal, are structures of particular interest.

The nuclei of the medullary cells with highly developed activity frequently present peculiar deformation of various appearances. The possible significance of such deformation may be understood in the 
light of the modern concept that the nucleus, especially nucleolus, plays a direct role in functional activity of the cell.

\section{Acknowledgments}

I wish to acknowledge the constant encouragement and constructive criticism received from Prof. Ch. Tog a ri. This study was supported in part by a grant in Aid for Developmental Scientific Research from the Ministry of Education.

\section{Literature cited}

Al t m a n n, H. W. 1952 Über den Funktionsformwechsel des Kernes im exokrinen Gewebe des Pankreas. Z. Krebsforsch., 58 : 632-645.

1955 Zur Morphologie der Wechselwirkung von Kern und Cytoplasma. Klin. Wochenschr., 33 : 306-314.

B a chmann, R. 1954 Die Nebenniere. In Möllendorff-Bargmann's Handtuch der mikr. Anat. d. Menschen, Bd. 6, T1. 5, pp. 1-952, Springer, Berlin.

$B$ ä nd er, A. 1950a Über zwei verschiedene chromaffine Zelitypen im Nebennierenmark und ihre Beziehungen zum Adrenalin- und Arterenolgehalt. Verh. Ant. Ges. Kiel, 1950: 172-176. (Cited from Bachmann, '54.)

1950b Die Beziehungen des 24-Studen-Rhythmus vegetativer Funktionen zum histologischen Funktionsbild endokriner Drüsen. Z. exper. Nied., $115: 229-250$. (Cited from Bachmann, '54.)

Ba rgman n, W. 1953 Über Kolloidbildung im Nebennierenmark. Z. Zelliorsch., 39: 232-240.

Bessho, M. 1927a Histological and histogenetic studies of the adrenal gland of the mouse. Aichi J. Med. Sci., 34 : 909-985. (Japanese.)

1927b Histological and histogenetic studies of the adrenal gland of the rat. Ibid. 34 : 1619-1645. (Japaness)

Cl a r a, M. 1937 Ûber die physiologische Regeneration der Nebennieremarkze:len beim Mensihen. Z. Zellforsch., $25: 221-235$.

Di et ri ch, A., und $\mathrm{H}$. Si e g m und 1923 Die Nebenniere und das chromaffine System (Paraganglien, Karotisdrüse, Steissdrüss). In Henke-Lubarsch's Handbuch der spez. pathol. Anatomie und Histo'ogie, Bd. 8, pp. 951-1089. Springer, Berlin.

En jo, K. 1947a Cytologlcal studies of the adrenal gland of man.

II. Cytology of the medullary cells, with special reference to the secretory phanomena. Kaibo Z., 23 : 41-42. (Japanese.)

$1947 \mathrm{~b}$ Cyto:ogical studies of the adrenal gland of man.

III. Nuclei of the medullary cells, with special reference to the amitosis, nucleolar vesicles and extrusion of formed materials. Ibid. $23: 43-44$. (Japanese.)

Era $n k$ o, O. 1952 On the histochemistry of the adrenal medulla of the rat, with spscial referance to acid phosphatase. Acta anat., 16: Suppl. 17, 1-60.

Félicin ne, L. 1902 Beitrag zur Anatomie der Nebenniere Anat. Anz., 22: 152-156. 1904 Ubber die Beziehungen zwischen dem Blutgefässsystem und den Zellen der Nebenniere. Arch. f. mikr. Anat., 63: 283-312. 
Gra u mann, W. 1956 Beobachtungen über Bildung und Sekretion perjodatreaktiver Stoffe im Nebennierenmark des Goldhamsters. Z. Anat., 119 : 415-430.

H a maza ki, Y. 1954 Physiology and pathology of the cellular nucleus. Nagai-Shoten, Osaka, Japan. (Japanese.)

It $0, T, 1953$ Observations on the development and structure of the adrenal medulla in the guinea pig. Fol. anat. jap., $25: 37-49$.

1954 Neurosecretory phenomena of the ganglion cells in the adrenal medulla of the golden hamster. Ibid. 26 : 221-226.

1956 Postnatal histogenesis of the adrenal cortex of the golden hamstar. Ibid. 29 : 67-91.

$\mathrm{K} \mathbf{n}$ i g g e, K. M. 1954 The effect of hypophysectomy on the adrenal gland of the hamster (Mesocricetus auratus). Am. J. Anat., 94 : 225-271.

Staemmler, M. 1933 Die Funktion des Nebennierenmarkes und ihr histologischer Ausdruck. Beitr. pathol. Anat., 91 : 30-58.

\section{Explanation of figures}

\section{PLATE 1}

1 Newborn male. Small sympathogonia are aggregated in clusters near the center of this figure. Zen ker-formol-acetic acid: H \& E. $\times 800$.

2 Six-day-old female. A mass of the medullary cells containing a relatively large space. Bou in: H \& E. $\times 800$.

3. Thirty-five-day-old male. Large light cells, arranged in compact masses, are present in the periphery of the medulla. B ou in: H \& E. $\times 400$.

4 One hundred and twenty-day-old male. A large medullary follicle of 8-figured shaps. Bou in: H \& E. $\times 400$.

5 Ninety-day-old male. A peripheral light call. Bou in: H \& E. $\times 2000$.

6 Seventy-day old female. Two peripheral light cells. The juxtanuclear area contains bosophilic granular materials around the periphery. Z en ker-formol-actic acid: $H$ e id enh a in's azan. $\times 2000$.

\section{PLATE 2}

7 One hundred-day-old male. Two peripheral light cells. A minute canalicule-like sapce is szen between these two cells. Zenker-formol: Heidenthain's iron hematoxylin. $\times 2000$.

8 Ninety-day-old female. A modullary follicle. The lumen contains erythrocytes. Bou in: H \& E. $\times 400$.

9 Ninety-flve-day-old male. A part of a folliclular wall. The apical area of the columnar cells contains varying amounts of fine vacuoles. $Z$ e $n k$ er-formol-acetic acid: $H$ \& E. $\times 800$.

10 One hundred and twenty-day-old female. Same as the above. The lumen of the follicle is present at the left side of this figure. Ciaccio: Heidenhain's iron hematoxylin. $\times 1700$.

11 One hundred and twenty-day-old male. A peripheral light cell is present at the center. The nucleus shows deep indentations on the suface directed toward the condensed juxtanuclear area. B o u in: H \& E. $\times 2000$.

12 Seventy-five-day-old female. Columnar cells forming a follicle. In the middle cell, the nucleolar material is extruded from the nucleus into the cytoplasm. $\mathrm{Z}$ en ke rformol-acetic acid: $H$ \& E. $\times 2000$.

13 One hundred-day-old male. A nucleus containing a large intranuclear inclusion. Bou in: H \& E. $\times 2000$.

14 One hundred-day-old male. A medullary cell at the center of this figure contains colloid materials. Bou in: H \& E. $\times 800$. 

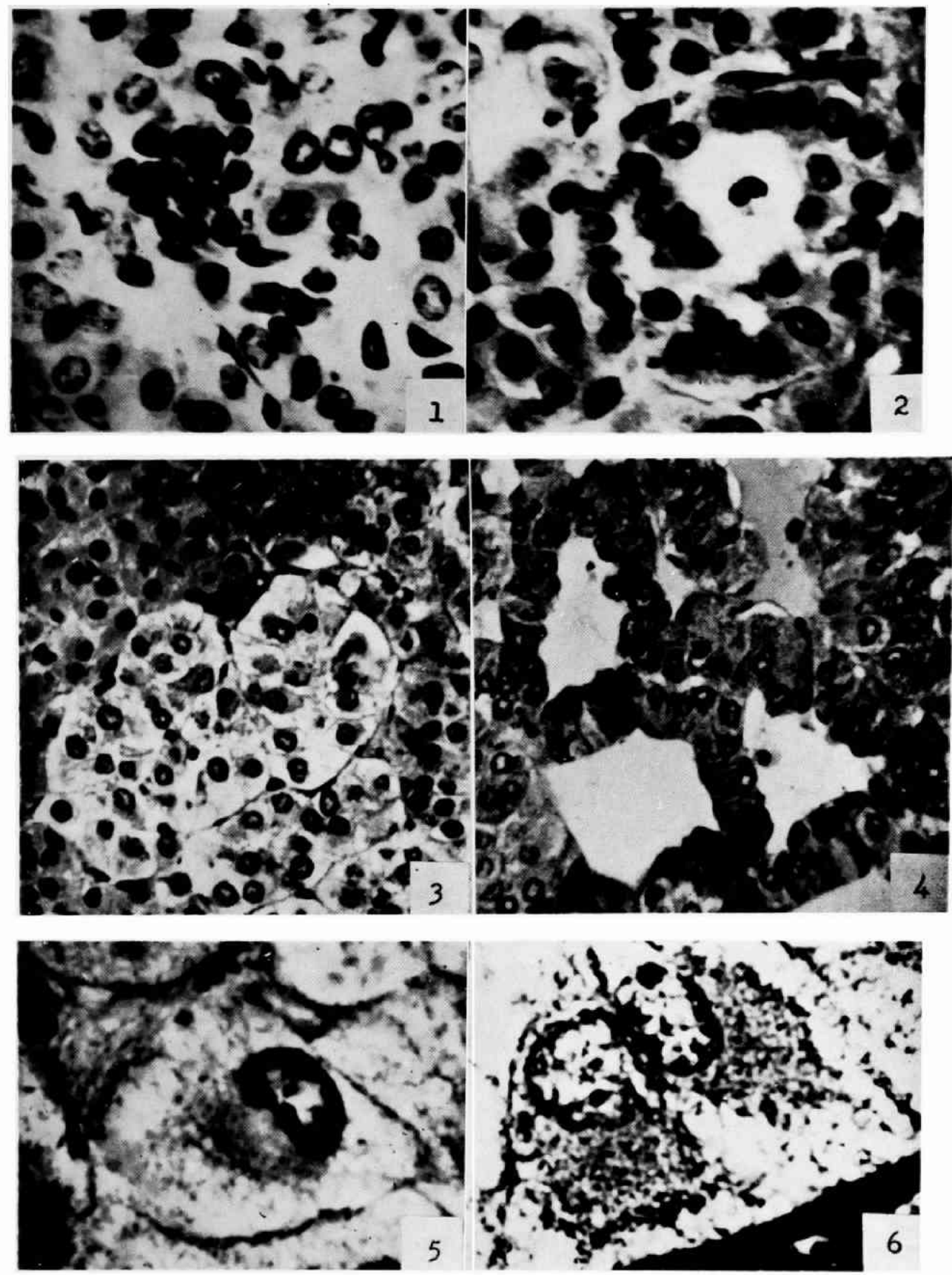

T. Ito 
Plate II

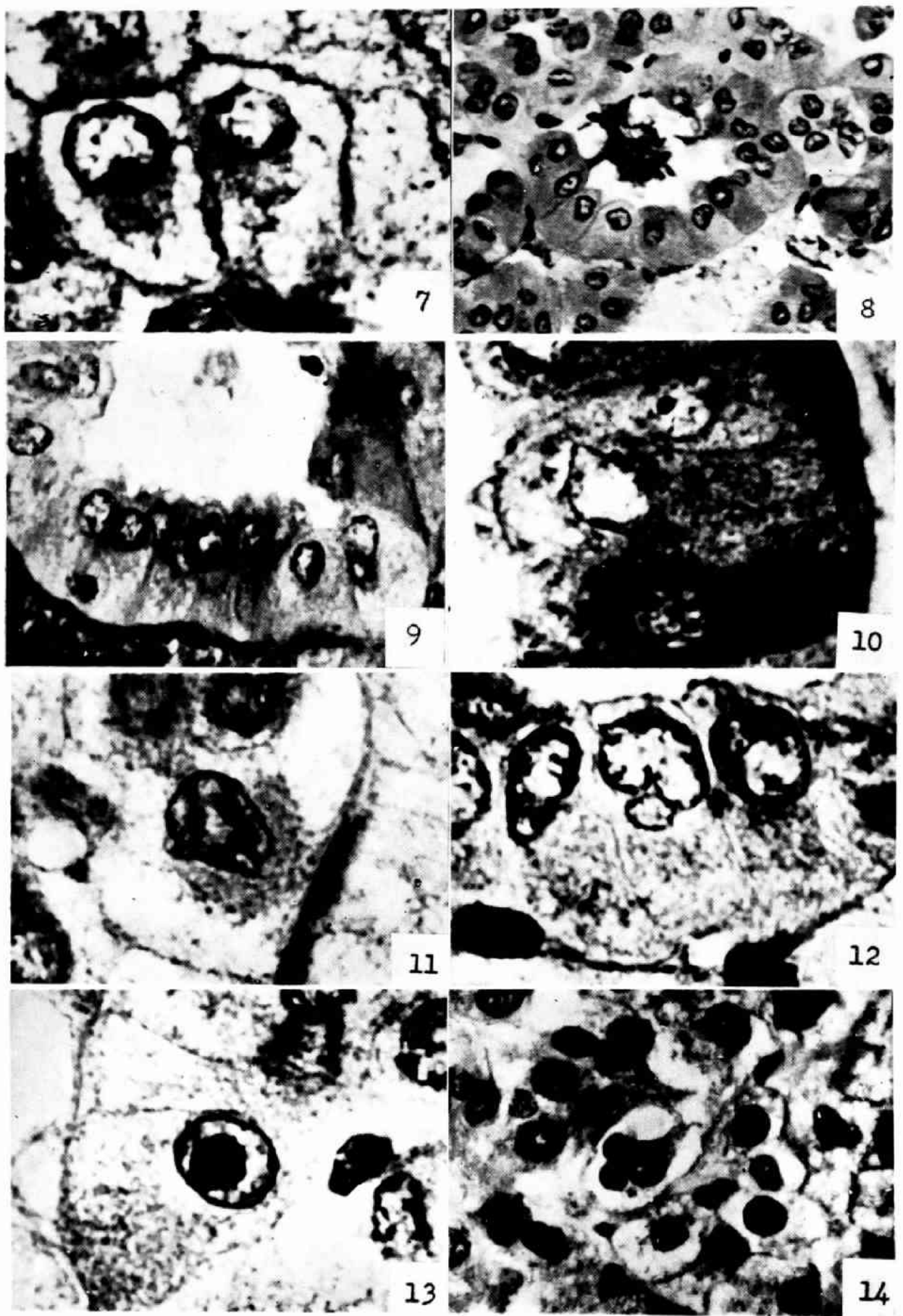

T. Ito 